\title{
AN ANATOMICAL STUDY OF VARIATION IN FISSURES AND LOBAR
} PATTERN OF HUMAN LUNGS

\section{C.Subadha ${ }^{1}$, M.Gayathri ${ }^{* 2}$.}

${ }^{1}$ Assistant Professor, Department of Anatomy, Govt. Dharmapuri Medical College, Dharmapuri, Tamilnadu, India.

*2 Assistant Professor, Department of Anatomy, Govt. Dharmapuri Medical College, Dharmapuri, Tamilnadu, India.

\section{ABSTRACT}

Introduction: Awareness of anatomical variations in lungs is essential during segmental or lobar resections of lungs. Hence the proposed aim of the study was to study the fissures and lobes of the lungs and their variations and to compare them with previous studies and to find their clinical implications.

Materials and Method: Seventy lungs obtained from cadavers in the department of anatomy, Govt Dharmapuri Medical College were used for study. Any variation in the fissures and lobes of the lungs and accessory fissure were studied.

Result: Out of seventy lungs studied, 32 were from right side and 38 were from left side. Out of 32 right lungs examined, the horizontal fissure was absent in 4 lungs (12.5\%), incomplete in 10 lungs (31.25\%), Complete in 18 lungs (56.25\%). Oblique fissure was incomplete in 5 lungs (16\%) and complete in 27 lungs (84\%). Out of 38 left lungs, the oblique fissure was incomplete in 8 lungs (21\%), complete in 30 lungs (79\%) and accessory fissure in 5 lungs.

Conclusion: Knowledge of such variations will be helpful to the radiologists, clinicians to make correct diagnosis and plan for the surgical procedure. This will help to reduce the morbidity and mortality associated with lung surgeries.

KEY WORDS: Fissures, Lobes, Variations, Lungs.

Address for Correspondence: Dr. M.Gayathri, Assistant Professor, Department of Anatomy, Govt.Dharmapuri Medical College, Dharmapuri-636701 Tamilnadu, India. Phone :7094743688 E-Mail: gayathriprabu5@gmail.com

Access this Article online

Quick Response code

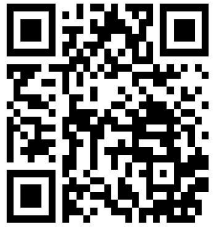

DOI: $10.16965 /$ ijar.2018.405
Journal Information

International Journal of Anatomy and Research

ICV for 2016 ISSN (E) 2321-4287 | ISSN (P) 2321-8967

90.30

https://www.ijmhr.org/ijar.htm

DOI-Prefix: https://dx.doi.org/10.16965/ijar

Article Information

Received: 11 Oct 2018

Peer Review: 12 Oct 2018

Revised: None
Accepted: 06 Dec 2018

Published (O): 05 Jan 2019

Published (P): 05 Jan 2019

\section{INTRODUCTION}

The lungs are divided into various lobes by a double layer of infolded reflections of visceral pleura called fissures. There are two types of pulmonary fissures: lobar or major fissure (MF) and accessory fissure (AF). Normal MF (oblique and horizontal fissures) consists of double layers of infolded invaginations of the visceral pleura [1].
The lungs are essential organ of respiration and are situated in the thoracic cavity on either side of the mediastinum. Amongst the pair, the right lung is divided into three lobes namely upper, middle and lower by oblique and horizontal fissures. The left lung is divided into two lobes namely upper and lower by oblique fissure. The arrangement of lung tissue into lobes by fissures facilitates the movements of the lobes in 
relation to one another thus helping in uniform expansion of the whole lung in inspiration [2].

In each lung, oblique fissure begins on medial surface at the posterosuperior part of hilum and crosses the posterior border of the lung $6 \mathrm{~cm}$ below the apex. At the posterior border, the fissure lies opposite at a surface point $2.5 \mathrm{~cm}$ lateral to the junction of $\mathrm{T} 3$ and $\mathrm{T} 4$ spines. Then, it descends forward across the costal surface to reach the inferior border of lung at 5 th intercostal space and follows the 6th costochondral junction about $7.5 \mathrm{~cm}$ lateral to the middle line. It finally ascends on the medial surface and ends at the lower end of hilum. The left oblique fissure is more vertical than the right. The short horizontal fissure separates the superior and middle lobes. The horizontal fissure begins at the oblique fissure near the midaxillary line, course horizontally along the costal surface, cuts anterior border at the level of 4th costal cartilage, and then passes backward on the mediastinal surface to the at the hilum [3].

The fissures may be complete when the lobes remain held together only at the hilum by the bronchi and pulmonary vessels, or they may be incomplete when there are areas of parenchymal fusion between the lobes, or they may be absent altogether. In addition to these fissures, accessory fissures may exist which are indicating junction between bronchopulmonary segments and they classified as superior accessory fissure, inferior accessory fissure, or left minor fissure. An incomplete major fissure may lead to disease spread, collateral air drift, or "incomplete fissure sign" or postoperative air leakage for pulmonary resection [4].

Craig and Walker [5] have proposed a fissural classification based on both the degree of completeness of the fissures and the location of the pulmonary artery at the base of the oblique fissure.

Grade I: Complete fissure with entirely separate lobes

Grade II: Complete visceral cleft but parenchymal fusion at the base of the fissure

Grade III: Visceral cleft evident for a part of the fissure

Grade IV: Complete fusion of lobes with no evident fissure line.
Variant anatomy may lead to misinterpretation of a radiograph or computed tomography (CT) scan. Certain radiological findings can mislead the diagnosis as in the cases of extra lobes, as it may misinterpret as lung lesions. Hence in the present study variation in the lobes and fissures of lungs from cadavers were studied and result are compared with previous studies, knowledge obtained may be useful to clinicians, surgeons and radiologist.

\section{MATERIALS AND METHODS}

With prior permission from concerned ethics committee, this cadaveric study was carried out in seventy lungs in the Department of Anatomy, Government Dharmapuri Medical College, Tamilnadu, India over a period of one year. Formalin fixed cadaveric lungs preserved in departmen-t as well as collected while doing undergraduate dissection classes; were studied meticulously irrespective of laterality and gender of the deceased.

\section{Inclusion criteria:}

Specimens in good physical condition without damage were included in the study.

\section{Exclusion criteria:}

The specimens having pathological lesions, marks of previous surgery, damaged during removal with gross abnormalities were not included in the study.

Following parameters were measured bilaterally by direct inspection:

a. Presence or absence of complete or incomplete fissure

\section{b. Presence of accessory fissure}

The anatomical classification proposed by Craig and Walker was followed to classify and determine the presence and completeness of fissures.

Fig. 1: Right lungs showing incomplete horizontal fissure.

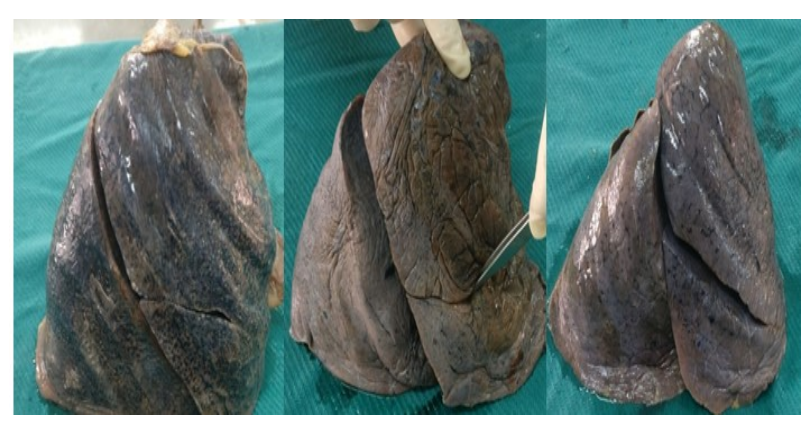


Fig. 2: Left lungs showing incomplete oblique fissure.

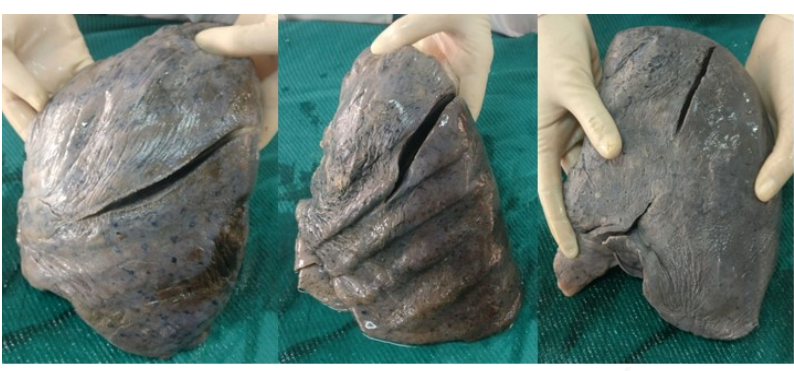

Fig. 3: Left lungs showing accessory fissure.

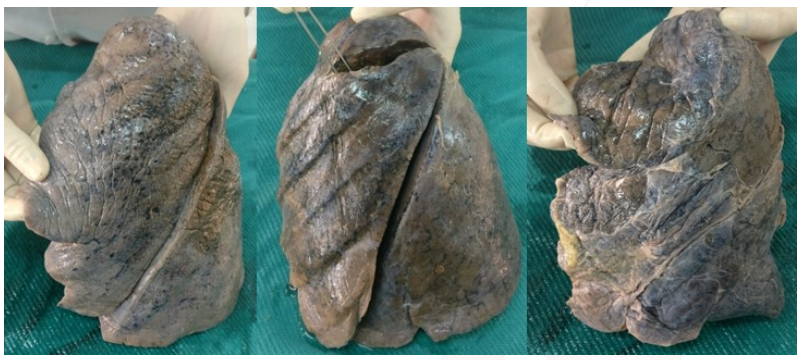

Fig. 4: Right lung showing incomplete horizontal and oblique fissure.

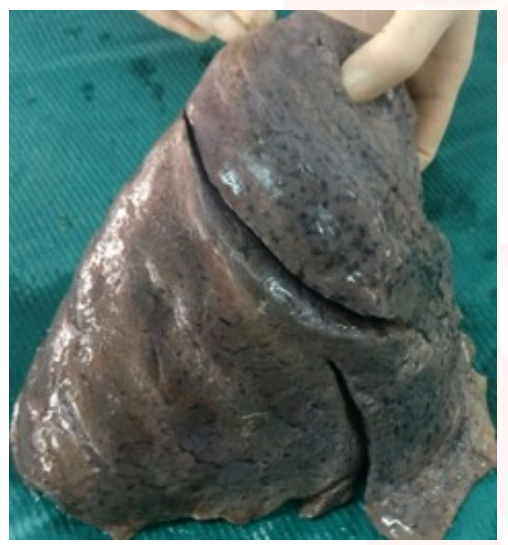

\section{RESULTS}

Out of seventy lungs studied, 32 were from right side and 38 were from left side. Out of 32 right lungs examined, the horizontal fissure was absent in 4 lungs (12.5\%), incomplete in 10 lungs (31.25\%), Complete in 18 lungs (56.25\%). Oblique fissure was absent in 0 lungs $(0 \%)$ and incomplete in 5 lungs (16\%), complete in 27 lungs (84\%). Out of 38 left lungs, the oblique fissure was incomplete in lungs $8(21 \%)$, complete in 30 lungs (79\%), absent in 0 lungs (0\%) and accessory fissure in 5 lungs.

Table 1: Incidence of fissure according to craig and walker's criteria.

\begin{tabular}{|c|c|c|c|}
\hline \multirow{2}{*}{ Grade } & \multicolumn{2}{|c|}{ Right lung ( $\mathrm{n}=32)$} & Left lung $(\mathrm{n}=38)$ \\
\cline { 2 - 4 } & Horizontal fissure & Oblique fissure & Oblique fissure \\
\hline I & $18(56.25 \%)$ & $27(84 \%)$ & $30(79 \%)$ \\
\hline II & $5(15.62 \%)$ & $2(6.25 \%)$ & $5(13 \%)$ \\
\hline III & $5(15.62 \%)$ & $3(9.37 \%)$ & $3(8 \%)$ \\
\hline IV & $4(12.5 \%)$ & $0(0 \%)$ & $0(0 \%)$ \\
\hline
\end{tabular}

Int J Anat Res 2019, 7(1.1):6059-63. ISSN 2321-4287
Table 2: Incidence of accessory fissure in left lung $(n=38)$.

\begin{tabular}{|l|c|c|}
\hline \multicolumn{2}{|c|}{ Incidence of accessory fissure in left lung $(\mathrm{n}=\mathbf{3 8})$} \\
\hline Total accessory fissure & $\begin{array}{c}\text { Total } \\
\text { number }\end{array}$ & Percentage \\
\hline Superior accessory fissure & 2 & $5.25 \%$ \\
\hline Inferior accessory fissure & 3 & $8 \%$ \\
\hline
\end{tabular}

pie chart showing variation in the horizontal fissure in right lung

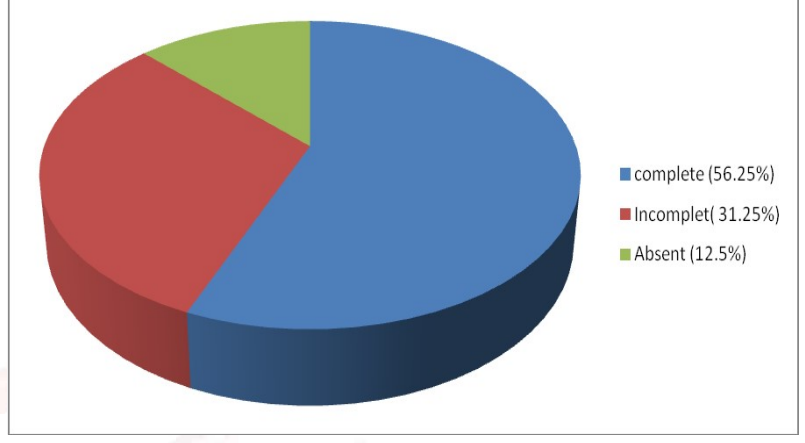

\section{DISCUSSION}

Cadavers are the best means to study the variant anatomy of any organ. Various researchers have noted and reported the anomalous anatomy of the lungs in human cadavers [2]. Ontogenetically the lung is a composite of endodermal and mesodermal tissues. The endoderm of the lung bud gives rise to the mucosal lining of the bronchi and to the epithelial cells of the alveoli. The vasculature of the lung \& the muscles $\&$ cartilage supporting the bronchi are derived from the foregut splanchnopleuric mesoderm, which covers the bronchi as they grow out from the mediastinum into the pleural space [6].

During development of the lungs numerous bronchopulmonary buds are formed and later they fuse completely except at the sites of fissure formation. This results in the formation of lobes and fissures. Incomplete fissure formation could be due to partial obliteration of these fissures. Accessory fissure could be the result of nonfusion of spaces between the bronchopulmonary buds which normally are obliterated. If there is any factor affecting the fusion in the developmental stage, there will be variations in the formation of lobes and fissures of the lung. In our literature survery,we could find a few reports on variations of the fissures of the lungs [3].

Shivaleela et al 2017 and vaibhav et al 2015 have 
Table 3: Comparisons of result of different studies on variation of lung fissures.

\begin{tabular}{|c|c|c|c|c|c|c|}
\hline \multirow{3}{*}{ Previous studies } & \multicolumn{4}{|c|}{ Right lung } & \multirow{2}{*}{\multicolumn{2}{|c|}{\begin{tabular}{|c|c|} 
Left lung \\
Oblique fissure
\end{tabular}}} \\
\hline & \multicolumn{2}{|c|}{ Oblique fissure } & \multicolumn{2}{|c|}{ Horizontal fissure } & & \\
\hline & $\begin{array}{c}\text { Absent } \\
(\%)\end{array}$ & $\begin{array}{c}\text { Incomplete } \\
\text { (\%) }\end{array}$ & $\begin{array}{c}\text { Absent } \\
(\%)\end{array}$ & $\begin{array}{c}\text { Incomplete } \\
\text { (\%) }\end{array}$ & $\begin{array}{c}\text { Absent } \\
(\%)\end{array}$ & $\begin{array}{c}\text { Incomplete } \\
(\%)\end{array}$ \\
\hline Present study 2017 & 0 & 16 & 12.5 & 31.25 & 0 & 21 \\
\hline Shivaleela C et al 2017[7] & 1 & 63 & 26 & 63 & 9 & 70 \\
\hline Gopalakrishna et al 2017[4] & 0 & 14 & 6 & 20 & 6 & 8 \\
\hline Thapa \& desai 2016[3] & 0 & 30 & 20 & 50 & 15 & 25 \\
\hline Vaibhav et al 2015 [8] & 2.56 & 10.26 & 23.08 & 20.51 & 0 & 5.26 \\
\hline Divya et al 2015 [9] & 0 & 10.7 & 21.4 & 50 & 7.4 & 14.8 \\
\hline Abhilash \&charulata 2015[10] & 0 & 17.25 & 6.89 & 31.03 & 4.76 & 28.8 \\
\hline Varalakshmi et al 2014 [11] & 4.8 & 2.1 & 10 & 30 & 7.3 & 10.6 \\
\hline
\end{tabular}

Table 4: Comparison of accessory fissure with other studies.

\begin{tabular}{|c|c|c|}
\hline \multirow{2}{*}{ Previous studies } & \multicolumn{2}{|c|}{ Accessory fissure } \\
\cline { 2 - 3 } & Right lung & Left lung \\
\hline Present study & 0 & $13.25 \%$ \\
\hline Jaideo M et al 2018 [12] & $28 \%$ & $16 \%$ \\
\hline Ambali MP et al [13] & $38 \%$ & $32 \%$ \\
\hline
\end{tabular}

reported varying percentage of incidence of absence of oblique fissure in the right lung, but in the present study, there was no incidence of absence of oblique fissure in accordance with Gopalakrishna et al 6 2017,Thapa \& desai 2016,Vaibhav et al(9) 2015,Divya et al 2015 \& Abhilash \&charulata 2015. In the present study, the left lung showed absent oblique fissure which is in conformity with vaibhav et al where as other author reported various percentage of absent oblique fissure.

Present study shows higher percentage of incidence of incomplete oblique fissure in the left lung when compared to the right lung Divya et al 2015 \& Abhilash \&charulata2015 but otherstudies showed the higher incidence of the percentage of incomplete oblique fissure of the right lung [Table 3]. The incidence of the percentage of incomplete horizontal fissure was similar to the Abhilash \&charulata2015 where as other studies showed a higher or lower value. The percentage of incidence of absence of horizontal fissure obtained does not coincide with other studies.

Acessory fissure seen in $13.25 \%$ of left lung. Some of the previous studies also report the presence of accessory fissure of lungs(table 4).Accessory fissures are sometimes present which appear differently on $\mathrm{X}$ rays and computed tomography scans and can mistakenly be confused with the areas of atelectasis or consolidation, pleural sacs or walls of bullae.[2]

\section{CONCLUSION}

The anatomy of the fissures is used as reliable landmarks in planning the pulmonary resection whereas incomplete fissures may contribute to post-operative air leakage. Incomplete fissures may alter the usual patterns of collapse of the lung seen in with endobronchial lesions and may also give rise to atypical appearance of pleural effusions thus complicating the identification of various pathologic conditions. Pneumonia and carcinoma in a particular lobe is often limited to that lobe alone by the fissures and may spread to adjacent lobes through the incomplete fissures. The knowledge of anatomy of fissures of lung may help to clarify confusing radiographic findings like extension of fluid into an incomplete major fissure or spread of various diseases through different pathways. Considering the clinical and surgical importance of such variations, the anatomical knowledge of variations in the fissures and lobes in the lungs may be important for Pulmonologists, Radiologists, Surgeons and Clinicians.

\section{Conflicts of Interests: None}

\section{REFERENCES}

[1]. Dogan N U et al, Major anatomic variations of pulmonary fissures and lobes on postmortem examination, Acta Clin Croat 2015;54:201-207.

[2]. Bincy M. George et al, Morphological variations of the lungs: a study conducted on Indian cadavers, Anat C Biol 2014;47:253-258.

[3]. Thapa $p$ et al,morphological variation of human lung fissures and lobes :An anatomical cadaveric study in north Karnataka, india. Indian Journal of Health Sciences 2016;9(3).

[4]. Gopalakrishna et al, a cadaveric study on morphological variations of fissures and lobes in the human lungs and its clinical significance. Journal of Experimental and Clinical Anatomy 2017;16(1). 
[5]. Craig S.R., Walker W.S. A proposed anatomical classification of the pulmonary fissures. J R Coll Surg Edinb 1997;42;233 4.

[6]. Enakshi ghosh et al,variations of fissures and lobes in human lungs - A multicentric cadaveric study from west Bengal, India. International Journal of Anatomy, Radiology and Surgery, 2013;2(1):5-8.

[7]. Shivaleela $C$ et al, A study of anatomical variations in patterns of fissures and lobes in human lungs: $A$ cadaveric study with clinical significances. International Journal of Anatomy and Research, 2018;6(1.1):4819-23.

[8]. Vaibhav Prakash Anjankar et al, Morphological study of lung lobes and fissures: anatomical basis of surgical and imaging techniques: International Journal of Anatomy and Research, 2017;5(1):3447-5.
[9]. Divya c et al, Anatomical study of pulmonary fissures and lobes. International Journal of recent scientific Research.2015;4(6):4554-57.

[10]. Abilasha et al,A Cadaveric study of morphological variations of lungs in vidarbha region. International journal of scientific research 2015;4;2163-6.

[11]. Varalakshmi KL et al,Morphological variations of fissures of lung.Indian journal of Applied Research 2014;4;457-69.

[12]. Jaideo $\mathrm{M}$ et al,variations in lobes and fissures International Journal of Anatomy and Research 2018;6(1.3):5020-23.

[13]. Ambali MP et al,variations of lung fissures:A Cadaveric study.journal of Krishna institute of medical sciences university.2014;3(1):85-89.

How to cite this article:

C.Subadha, M.Gayathri. AN ANATOMICAL STUDY OF VARIATION

IN FISSURES AND LOBAR PATTERN OF HUMAN LUNGS. Int J Anat Res 2019;7(1.1):6059-6063. DOI: 10.16965/ijar.2018.405 